\title{
M.Ed Graduates' Perceptions of Thesis Supervision, Writing and Defence
}

\author{
T.D. Mushoriwa \\ University of Fort Hare, Alice Campus, Bag X1314, RSA. \\ Email:Tmushoriwa@ufh.ac.za
}

\section{G.Nyakutse}

University of Lupane; Zimbabwe

\section{Doi:10.5901/mjss.2014.v5n8p319}

Abstract

This study explored M.Ed graduates' perceptions of thesis supervision, writing and defence in the M.Ed Programme in the Faculty of Education, University of Swaziland. The main objective was to find out how M.Ed graduates think and feel about thesis supervision, writing and defence, with the ultimate aim of improving thesis supervision and writing and helping students successfully defend their theses. A questionnaire, largely using likert-type and open-ended items, sourced data from the participants $(n=80$; females $=60 \%$, mean age $=33.6$ years; $S D$ 1.2). Follow-up interviews were also conducted with some of the participants $(n=16)$. Data were analysed using the likert scale analysis procedures described in the article. Overall, the study revealed that most participants (86\%) viewed thesis supervision, writing and defence in the faculty favourably although there were areas of serious concern to some graduates. These included, among others, difficulty in identifying a research topic, locating related literature, deciding on which aspect of related literature to include, deciding on how to present the data and being nervous during defence. Key recommendations based on the findings of the study were that all M.Ed students should have done a research project in their first degree and that supervisors should render more assistance and support to students during thesis writing. Furthermore, students need thesis defence practice-runs before they finally defend their theses before a panel of examiners.

Keywords: perceptions, supervision, thesis writing, thesis defence, supervision models, practice-runs.

\section{Introduction}

The current study tapped M.Ed graduates' perceptions of thesis supervision , writing and defence. The overall aim of the study was to establish two issues; how thesis supervision, writing and defense in the faculty are viewed by students, and also to capture problematic areas in thesis supervision, writing and defence in order to improve this area of students' learning.

A study of this nature takes lofty significance given that it acts as feedback from the 'consumers', and this has the potential to improve the quality of thesis supervision, writing and defence. The findings of the study, will hopefully, encourage supervisors to re-examine their supervision practices, styles and strategies with the hope of improving them. Given that supervision is a challenging and subtle form of teaching, more research on it is needed if we are to understand its complexities and challenges. It is perhaps for this reason that Lee (2007) says that thesis supervision should receive greater attention than it currently receives because the quality of the thesis suggests the kind of supervision and writing that were done and the quality of input from examiners during defense.

As already intimated, the present study therefore sought to find out how graduates of the programme perceive the supervision they received and the nature of problems encountered.

\section{Background of the Study}

Thesis writing is core and critical at Masters level. For some universities, their masters programmes are by thesis only while for other universities, there is a combination of a thesis and coursework. The University of Swaziland, like many other universities, uses the second option. It is important to note at this juncture that M.Ed. was chosen because at the moment, the University of Swaziland does not have PhD programmes.

During the second year of study, students are expected to come up with research topics. They are then assigned 
to supervisors according to expertise available. Students then work with their supervisors and should be ready to present their proposals to the department within six months. When the theses have been completed and the supervisor(s) approve(s) the theses as defensible, they are sent to external examiners. Ideally each thesis should be examined by two examiners but due to expense, one supervisor is seen as enough. Once the external examiner is satisfied, the common practice is, just like in many other universities, to have students defend their theses. Usually students defend their theses before a panel of external examiners and the students' supervisors. Among other things, the aim is to see whether the student's thesis is hislher own work and whether the student clearly understands the methodological procedures of the study. The fact that there will be examiners from other universities and that if the student fails to defend hislher thesis successfully helshe can either fail or be referred, makes the exercise very strenuous for many students. The present study therefore found it necessary to examine participants' feelings regarding this exercise and see if ways to mitigate its possible negative effects could be found.

\section{Objectives of the Study}

The objectives of the study were to:

- establish the perceptions of M.Ed graduates regarding thesis supervision, writing and defense.

- capture problematic areas in thesis supervision, writing and defence with a view to improving thesis supervision, writing and defence.

\section{Literature Review}

The review of related literature focused on key variables in the study, which are:

- Perceptions and how they influence behaviour or action

- Thesis supervision, writing and defence.

\subsection{Perceptions}

Rajecki (1982) argues that perceptions are such an important area to study because they influence what individuals think and feel about certain issues. For him, perceptions, which include attitudes, are critical in that they influence a person's convictions about how things ought to be done. In this study, it was assumed that M.Ed graduates have certain perceptions about thesis supervision writing and defence regarding how these ought to be done. It is these perceptions that this study set out to investigate.

\subsection{Thesis supervision, writing and defence.}

The area of thesis supervision, writing and defence seems to have been neglected by researchers as evidenced by sparse literature on the subject, despite the fact that there are problems in thesis supervision, writing and defence that include, among other things, long completion times, high drop out rates and failure to successfully defend the thesis. As already seen, Lee (2007) contends that thesis supervision, writing and defence should certainly receive greater attention than they currently receive because the quality of the thesis suggests the kind of supervision and writing that were done and the quality of suggestions for improvement made during defence. For Pearson and Kayrooz (2004), most supervisors tend to supervise students the way they themselves were supervised and thus perpetuate a rather rigid tradition of thesis supervision. Such practice negates and overlooks the fact that thesis supervision requires resourcefulness, expert coaching, facilitative interaction and mentoring, given the many challenges students face in this area of their study.

Grant (2005) thinks that some of the challenges in thesis supervision result from differences among supervisors mainly as a function of, among other things, their different theoretical orientations or supervision practices/models to which they subscribe. Lee (2007) says that these differences in the way different people supervise students may be unhealthy, particularly where students change hands during thesis writing. In such cases, there are reports of students being asked to almost start the thesis all over because of differences in supervisors (Lee, 2007). To avoid such situations, Lee (2007) recommends a common conceptual framework or approach to thesis supervision, which acts as a broad guideline for thesis supervisors. To the present writers, a common conceptual framework for supervising students may be made possible by adopting what may be considered the 'best elements' from the currently existing supervision models.

Grant (2005) identified four supervisory models or practices that include the Psychological Model, the Traditional 
Academic Model, the Techo-Scientific Model and the Neo-Liberal Model.

\subsection{The Psychological Model}

In this model, the supervisor shows a lot of concern and care about what the student is doing. He/she is an expert professional who motivates, inspires and supports the student. This model is sometimes referred to as the Pastoral Model because the supervisor shows very high levels of pastoral support to the student while at the same time challenging his/her students to pursue and explore their own interest. Thus, the supervisor in this model is flexible and 'sensible' (Grant, 2005). Since relationships between the student and the supervisor are cordial, students tend to work hard and they normally complete their theses in time. They do not want to disappoint their supervisor.

\subsection{The Traditional Academic Model}

This model reflects conservative norms of academic life. The Trad-supervisor is a master of his/her discipline, a scholar whose aim is to test the intellectual capacity of his/her students. Students working under him/her often find thesis writing very strenuous. He keeps some distance between himlher and hislher students and usually marks students work thoroughly. Helshe expects a very high standard from the students.

\subsection{The Techno-Scientific Model}

This model believes that research is an orderly, co-operatively planned and executed activity which requires proper training in research methods. The supervisor closely monitors the student's work and when shortfalls are noticed, he/she prescribes appropriate skills-training. This model is akin to the Directorial Model (Grant, 2005) because the supervisor stresses structure in his/her dealings with the student. The supervisor is task-driven and tends to administer direction to the thesis without giving much support to the student. The relationship is that of expert versus research novice. The power relationships in this model are marked by intimidatory tendencies on the part of the supervisor.

\subsection{The Neo-Liberal Model}

This model emphasises institutional practices and contractual obligations. To this end, accountability on both parties is a priority. Relationships are of a quasi-legal nature since supervision contracts, charters of rights and grievance procedures are stressed (Grant, 2005). This kind of relationship means that each of the two parties 'fears' to go over-bounds. Clearly such a relationship is not productive to thesis supervision and writing.

Although Grant (2005) identifies only these four supervision models, he concedes that another model, the laissezfaire type, has been conceived. Here, the supervisor provides low levels of support and structure but is willing to offer input at certain key stages of the thesis. The student is encouraged to work independently most of the time. This lack of proper guidance or benign neglect can disillusion some students or can result in poor quality work. Sometimes work submitted takes long to be marked and returned to the student. In some cases, there is no evidence of marking at all.

Students working with such a supervisor usual fail to complete their theses within the stipulated time. One of the key roles of a supervisor is not only to ensure student progress but also to ensure high standards by sharing his/her expertise with the student. In fact, research studies, for example, Mapesela \& Wilkinson (2005) and Okwilagwe (2002) have demonstrated that students are more committed to their work if help and guidance were more readily available and their efforts appreciated.

It is clear that these thesis supervision models articulate a particular way of thinking, conceptualising and practising supervision. They not only reflect the amount of guidance students get, but also their relationships with their supervisors; and consequently how they perceive the act of thesis supervision. Thus, effective supervisory practices require the establishment of good working relationships which ensure that the students find the supervisor approachable all the time.

For Grant (2005), each of these models has its student counterparts. This implies that, for example, while you may find students who cannot and do not want to do things without proper guidance, others prefer to do their work independently most of the time. If this be the case, then clearly some of our supervision styles or practices do not meet the supervision needs of some of our students. This has grave consequences because research studies such as those by Jasonbeck (1984), Brenman (1985) Kolb (1987) and Stanley \&Beasley (2005) have shown that when students are taught in ways that correspond with their unique learning characteristics or where the teaching matches the learning orientation of the student, the supervisee attains significantly better. This suggests that supervisors should not supervise students 
according to their own preferred styles but rather vary styles to accommodate students' preferred ways of learning. Ensnaring students in our own supervision styles tends to disadvantage many students, hence, the need for an eclectic approach. It is perhaps for this reason that Lee (2007) says that effective supervisors seem to be those who are flexible and able to cross interdisciplinary boundaries.

Almost all universities require their Masters and PhD students to defend their theses. Among other things, as already seen, the aim is to:

- check if candidate conducted original first class research .Many candidates make the mistake of showing little understanding of their work.

- if candidate can effectively communicate the methodological procedures and results of hislher study.

- see if candidate is able to show the dent or lacuna in knowledge that hislher study is filling.

- indicate why the problem is interesting or important.

For Brabazon (2010), thesis defense implies attack, so the student must expect to be academically attacked but helshe should remain calm. In some institutions, the candidate is interrogated by an international panel of experts, in other universities the candidate is examined by the institution's experts and still in some, they are examined by the faculty's experts while in other universities, there is no thesis defense and therefore no comparison of standards with other universities at the thesis defense level. These universities simply send their students' theses to two or three examiners and their combined decision is final.

Literature reviewed in this study indicates that although little has been documented about thesis supervision, supervisory practices and thesis writing, to the present writers' knowledge, no study focusing on students' perceptions of thesis supervision, writing and defense, at least in Swaziland, has been conducted. This gap in research makes the present study necessary, especially given that perceptions people have on certain issues not only affect the degree to which they commit themselves to those issues or tasks, but also how they eventually relate to those they interact with in the process of doing those tasks. Students can have certain attitudes towards both their supervisor and the supervision process as a function of, among other things, their perception of the supervisor and the supervision process.

\section{Methodology}

\subsection{Research Design}

The survey research design was used in this study principally because, according to Van Dalen (1979), it allows the collection of data that can be used to evaluate current practices in order to improve them. The current study aimed at capturing the perceptions of M.Ed graduates regarding thesis supervision, writing and defense with a view to improving them. Thus, the survey research design was preferred because it was found to be an effective tool in determining the opinions, attitudes, preferences and perceptions the students.

\subsection{Sample}

The study sample involved M.Ed graduates who graduated from the University of Swaziland's Faculty of Education between 2006 and 2011. A total of 80 graduates were identified and eventually involved in the study (females $=60 \%=48$; mean age $=33.6$ years; $S D=1.2$ )

\subsection{Instruments}

A survey questionnaire, supplemented by follow-up interviews, was used to source data from the participants. The questionnaire developed by the researchers, used three response formats (Yes-No; Likert-type items and open-ended questions) not only for controlling response bias, but also for ensuring that questions asked really tapped the information required.

Follow-up interviews which were held with 16 of the participants were meant to probe into subtle issues and unexpected responses which the participants raised in their responses to the questionnaire items. Open-ended questions allowed the hearing of the graduates' perceptions regarding thesis supervision, writing and defense as much as possible but of course within the confines of the research design. 


\subsubsection{Validity and Reliability of Instrument}

The questionnaire was given to four (4) raters who were considered experts in the study of perceptions. These experts were asked to check the suitability (validity) of the questionnaire and also to independently rate it (out of 10) for purposes of testing its reliability. Inter-rater reliability analysis yielded a sufficiently acceptable coefficient (0.6); hence, the questionnaire was taken as valid and reliable.

\subsubsection{Pilot Study}

The questionnaire was test-run with six (6) M.Ed graduates who completed their M.Ed studies prior to 2006. After making minor amendments and modifications, the questionnaire was adopted for use with the study sample.

\subsubsection{Scoring the Likert Scale}

As already pointed out, the bulk of the questionnaire items (40 out of 47) were in likert form using Strongly Agree (SA); Agree (A); Undecided (U); Disagree (D) and Strongly Disagree (SD). Scoring the likert scale required the following:

Table 1: Scoring the Likert Scale

\begin{tabular}{|l|ccccc|}
\hline & SA & A & U & D & SD \\
\hline Positive Statement & 5 & 4 & 3 & 2 & 1 \\
Negative Statement & 1 & 2 & 3 & 4 & 5 \\
\hline
\end{tabular}

What Table 1 means is that, like in all likert scale analysis procedures, items were first classified into positive and negative. Positive statements were then scored 5 for Strongly Agree down to 1 for Strongly Disagree while negative statements were scored 1 for Strongly Agree up to 5 for Strongly Disagree.

Next, item scores for each respondent were added up to obtain a total score. Since the questionnaire had forty (40) likert type items, there was a maximum possible score of $200(5 \times 40)$ and a necessary minimum score of $40(1 \times 40)$. To see whether the respondents' perceptions were positive or negative, a score above the mid-way of the possible maximum score $(200 / 2=100)$ was regarded as positive while scores below that were regarded as negative. The neutral point (100) was not included for purpose of analysis in order to make the results directional (Fishbein, 1975).

Since in studies of this nature high scale scores mean favourable perception and low scale scores mean unfavourable perception, it means that overall, if there are more high scale scores than low scale scores, we can conclude that the majority of M.Ed graduates involved in this study view thesis supervision, writing and defense in the Faculty of Education, University of Swaziland, favourably. If there are more low scale scores, then we can conclude that the graduates are largely not satisfied with thesis supervision, writing and defence in the faculty.

\section{Data Presentation and Discussion}

After transferring the data to coding sheets and key-punching them for analysis, the following results were obtained.

Total No. of Low Scale Scores $(40-99)=11(14 \%)$

Total No. of High Scale Scores $(101-200)=69(86 \%)$

Since the majority of scores $(69=86 \%)$ are high scale scores, it means that the majority of participants(86\%) in this study had positive perceptions of thesis supervision, writing and defence in the faculty.

The above indicates that most of the M.Ed students involved in this study agree that thesis supervision, writing and defence are done well in the Faculty of Education, University of Swaziland. These findings are consistent with research findings elsewhere. Mapesela \& Wilkinson (2005) conducted a study involving postgraduate students at the University of Free State, South Africa, and found that most of the students felt that the supervision they received for their mini-dissertations was quite adequate and useful.

The forty (40) likert type questionnaire items were themselves taken as rating scales and as such, were analysed individually. Table 2 below shows the items and responses. 
Table 2: Participants Showing Favourable or Unfavourable Perceptions Towards each Questionnaire Item( $\mathrm{N}=80)$.

\begin{tabular}{|c|c|c|}
\hline & \multicolumn{2}{|c|}{ Responses } \\
\hline & $\begin{array}{l}\text { No. with favourable } \\
\text { perception ("Yes") }\end{array}$ & $\begin{array}{l}\text { No. with unfavourable } \\
\text { perception ("No") }\end{array}$ \\
\hline $\begin{array}{l}\text { 1. The research project I did for my undergraduate studies equipped me with } \\
\text { skills necessary for my thesis at Masters' level. }\end{array}$ & $71(88.75 \%)$ & $9(11.25 \%)$ \\
\hline 2. Before I embarked on my M.Ed research, I felt mentally ready to do it. & $50(62.5 \%)$ & $3(37.5 \%)$ \\
\hline $\begin{array}{l}\text { 3. Before embarking on my research, I had a clear understanding of what } \\
\text { research is. }\end{array}$ & $65(81.25 \%)$ & $15(18.75 \%)$ \\
\hline 4. When I was to start my thesis, I had a clear idea where to start & $64(80 \%)$ & $16(20 \%)$ \\
\hline 5. I started my research soon after getting my examination results. & $33(41.5 \%)$ & $47(58.75 \%)$ \\
\hline 6. It was easy for me to identify a research topic. & $10(12.5 \%)$ & $70(87.5 \%)$ \\
\hline 7. My supervisor helped me to identify a research topic. & $40(50 \%)$ & $40(50 \%)$ \\
\hline 8. I was sure about what is meant by reviewing related literature & $68(85 \%)$ & $12(15 \%)$ \\
\hline 9. Related literature was easily available & $22(27.5 \%)$ & $58(72.5 \%)$ \\
\hline $\begin{array}{l}\text { 10. I found it easy to decide on which aspect of related literature to include in } \\
\text { the thesis. }\end{array}$ & $10(12.5 \%)$ & $70(87.5 \%)$ \\
\hline 11. I had no difficulty choosing a research method & $35(43.75 \%)$ & $45(56.25 \%)$ \\
\hline 12. I had no problem in deciding on what data to collect & $30(37.5 \%)$ & $50(62.5 \%)$ \\
\hline 13. I had problems in designing an instrument to use to collect data & $5(6.25 \%)$ & $75(93.75 \%)$ \\
\hline 14. I had difficulty in validating the instrument & $17(21.25 \%)$ & $63(78.75 \%)$ \\
\hline 15. I had difficulty in testing the instrument for reliability & $18(22.5 \%)$ & $62(77.5 \%)$ \\
\hline 16. Deciding on how to present the data was easy & $10(12.5 \%)$ & $70(87.5 \%)$ \\
\hline 17. I kept postponing starting on my thesis until there was little time left & $23(28.75 \%)$ & $57(71.25 \%)$ \\
\hline 18. Sometimes I kept away from my supervisor & $38(47.5 \%)$ & $42(52.5 \%)$ \\
\hline 19. Sometimes the supervisor had to contact me to bring my work & $25(31.25 \%)$ & $55(68.75 \%)$ \\
\hline 20. I had to rush in the end in order to complete my thesis. & $50(62.5 \%$ & $30(37.5 \%)$ \\
\hline 21. I disliked being required to re-do work when I felt it was okay. & $36(45 \%)$ & $44(55 \%)$ \\
\hline 22. I found it hard to work with my supervisor & $28(35 \%)$ & $52(65 \%)$ \\
\hline 23. I had confidence in my supervisor. & $40(50 \%)$ & $40(50 \%)$ \\
\hline $\begin{array}{l}\text { 24. My supervisor showed little interest, giving the impression that I was } \\
\text { bothering him/her }\end{array}$ & $0(0 \%)$ & $80(100 \%)$ \\
\hline 25. Comments by the supervisor were sometimes confusing. & $20(25 \%)$ & $60(75 \%)$ \\
\hline 26. Comments by the supervisor were sometimes contradictory. & $17(21.25 \%)$ & $63(78.75 \%)$ \\
\hline 27. My supervisor was good and offered specific guidance & $65(81.25 \%)$ & $15(18.75 \%)$ \\
\hline $\begin{array}{l}\text { 28. The supervisor made comments that were useful and helped me to make } \\
\text { progress. }\end{array}$ & $70(87.5 \%)$ & $10(12.5 \%)$ \\
\hline 29. The supervisor kept work for weeks and each & $14(17.5 \%)$ & $66(82.5 \%)$ \\
\hline 30. The supervisor encouraged me to work steadily & $50(62.5 \%)$ & $30(37.5 \%)$ \\
\hline 31. The supervisor rushed me only when deadlines were close. & $12(15 \%)$ & $70(85 \%)$ \\
\hline 32. My supervisor was always available for consultation. & $60(75 \%)$ & $20(25 \%)$ \\
\hline 33. The oral presentation of my thesis was easy for me. & $32(40 \%)$ & $48(60 \%)$ \\
\hline $\begin{array}{l}\text { 34. I received adequate preparation from the Institute of Post-Graduate } \\
\text { Studies for the oral presentation. }\end{array}$ & $20(25 \%)$ & $60(75 \%)$ \\
\hline $\begin{array}{l}\text { 35. The sight of so many people made me nervous during the oral } \\
\text { presentation. }\end{array}$ & $50(62.5 \%)$ & $30(37.5 \%)$ \\
\hline $\begin{array}{l}\text { 36. The questions that were asked during the oral presentation were easy for } \\
\text { me to respond to. }\end{array}$ & $40(50 \%)$ & $40(50 \%)$ \\
\hline 37. I felt that questions asked during my oral presentation were to "get" me. & $11(13.75 \%)$ & $69(86.25 \%)$ \\
\hline $\begin{array}{l}\text { 38. When I was asked to leave the presentation room after the oral exam, I } \\
\text { felt I had done well. }\end{array}$ & $59(73.75 \%)$ & $21(26.25 \%)$ \\
\hline 39. I was confused during the whole presentation exercise. & $7(8.75 \%)$ & $73(91.25 \%)$ \\
\hline 40. My supervisor assisted me in making changes in my thesis. & $50(62.5 \%)$ & $30(37.5 \%)$ \\
\hline
\end{tabular}

From Table 2, all participants, (100\%) agreed that their supervisors showed interest in their work. As already seen, this support from supervisors is critical if students are to persevere and succeed in writing and defending their theses. About 
$89 \%$ of the participants acknowledged that the knowledge and skills gained during the research projects done in the undergraduate courses helped them when they were doing their theses. Mapesela \& Wilkinson (2005) also noted that insufficient background and experience in research was one of the major challenges facing postgraduate students when doing research. This is the reason why perhaps, students involved in the current study acknowledged the usefulness of the knowledge and skills gained when they were doing undergraduate projects.

Graduates in the current study also had no problems with designing, validating and testing the validity of their research instruments. Interview data showed that many of them had done this well in their research methods course. Other issues responded to positively by the majority of the graduates were that they had a clear understanding of research before they began their M.Ed thesis (Item $3-81.25 \%$ ), had some idea about where to start the research, (Item $4-80 \%$ ) knew the meaning of literature review, (Item 8 - 85\%) started work promptly, (Item $18-52.5 \%$ ) kept in touch with their supervisors, (Item $18-52.5 \%$ ) worked well with their supervisors, (Item 22 - 65\%) found comments by supervisors useful, (Item 18 - 52.5\%) valued the guidance offered (Item $27-81.25 \%$ ) and that their supervisors were always available when they needed them (Item $32-75 \%$ ). About 63\% (Item 2) said they were mentally ready to do the research from the beginning and worked steadily throughout the research process with the encouragement of the supervisors. About $63 \%$ (Item 35 ) said they were intimidated by the oral presentation panel while $50 \%$ felt that questions asked at the presentation were relatively easy (Item 36 ).

Data from Table 2 also show that one of the problematic areas for many of the participants was identifying a research topic (Item $6-87.5 \%$ ) and deciding on the best way to present data (Item $16-87.5 \%$ ). Other areas that the participants found difficult were getting access to related literature (Item $9-72.5 \%$ ) deciding on what aspect of related literature to include (Item 10 - 87.5\%) choice of a research method (Item $11-56.25 \%$ ) and deciding which data to collect (Item $12-62.5 \%$ ). Also challenging was facing the oral presentation panel (Item $35-62.5 \%$ ). Data from interviews revealed that many of the participants wished they had been coached on how to defend their thesis. They said that they lacked confidence because they did not have knowledge regarding the defence process. For Brabazon(2010), students should have two or three thesis defense practice-runs with their supervisors and colleagues not only for developing confidence but also for getting suggestions for improvement. It is also important for students to thoroughly know their work; they are the experts of their theses. This creates confidence during presentation. In the present writers' view, thesis defence is really also a defence of the self, the better one prepares for one's defence, the stronger and more confident one is likely to feel.

Data from open-ended questions reflected the personal nature of the research process and the intimacy of the supervision process. Two of the participants had this to say during interviews:

"I thought very hard before I applied for the M.Ed Programme. The research method course helped a lot but I was not sure whether I would manage a thesis."

"I was not mentally ready because I stayed a long time before enrolling for Masters. I had lost touch. I did not know what research was and I needed more guidance."

The above quotes indicate that for those M.Ed graduates who had been out of institutions of higher learning for a long time, knowledge and skills gained during that time may have been forgotten, making the new task of research and thesis writing more challenging and even threatening.

On beginning the research process itself, participants reported many delays. The following were the common challenges identified by the participants in their own words.

- "The most difficult part was identifying a research topic".

- "I did not have direction. I had many topics without understanding most of them. I changed my topic many times before settling for one."

- " "I could not come up with a research topic. I kept jumping from one topic to another."

- "I was not sure what is meant by review of related literature. To me it was like I needed to list without any discussion. I made a lot of mistakes before showing the relatedness of the literature"

- "Data were vast and very difficult to handle. I did not know what statistic to use. My supervisor too, admitted having limited knowledge of statistics. This is a real problem, many students end up doing qualitative reearch where quantitative research could have produced more meaningful results."

These comments indicate that many students have problems regarding the choice of a research topic. Sometimes students choose topics that are not feasible or topics that are not within their competence or expertise. These comments also indicate that in some cases, both supervisors and supervisees have problems regarding the use of statistics in 
analysing data. This tends to limit quantitative research among many students.

On the supervisor and he supervision process, many supervisors were reported to have interest in their student's work. One participant commented: "It was nice to work with my supervisor; he proved to have mastery of research." Another said, "He always had time for me and made sure I did my work."

Comments about supervisors and the supervision process were a mixed bag although to a large extent positive. Below are some of the comments from some participants:

- "My supervisor was helpful, even helped me after hours."

- " "Comments by the supervisor were speedy, clear and sensible and made work easier and faster for me."

- "Most of the time my work was ready and some comments were made in my presence."

- "Sometimes I felt he (supervisor) was too harsh, hard and did not understand or appreciate my effort. He is a hard-worker and can push you to the limit, believe you me, you come out good if not best. Many students avoid choosing him, he is extremely knowledgeable as far as research and thesis writing are concerned."

- "When he was there, he showed great interest, but he was not there in most cases. Yes, I benefited a lot from the comments he made but the progress was hindered by his absence. He would take time looking at each section, meanwhile I would not move. He seemed not to care about time, I was the one trying to rush things."

- "She was not available, even disappeared the week the thesis was due. Sometimes she would call to say she wasn't coming."

As much as the participants were generally happy with the supervision process, there were some aspects that, for some of them, left much to be desired. For example, the need for student and supervisor to meet regularly to ensure that critical issues are discussed without the pressure of time. These comments also indicate the need for supervisors not to be too harsh with students and to show appreciation of the student's effort where this is due. Students tend to produce better work with a hard-working and nurturing supervisor.

Supervisors were also expected to be always available for consultation; discourage students from requesting extension and not to keep students' work for weeks. They were also required to avoid confrontation with students and cultivate a culture of mutual respect.

\section{Conclusion}

Findings from this study confirm literature and research findings by other researchers. Some participants found their supervisors knowledgeable in research, giving them valuable comments on their work, a view shared by Moses (1994) and Spear (2000) who are of the view that supervisors must be competent in the area of research. Where the supervisor feels incompetent or unfamiliar with the area of research, there is need for a co-supervisor. Also of interest in this study is the fact that the participants themselves clearly stated what they perceived to be the responsibilities of the students which included driving the research process by starting early, ensuring that they read adequately and maintaining regular fixed contact time with the supervisor. Not only did they have some knowledge of what their responsibilities were in the complex world of research and thesis writing, but they also pointed out areas of knowledge- and skills- deficit such as choosing a research topic, identifying related literature and data analysis. Another picture that has emerged is that initially, for some students, thesis writing is a confusing, traumatic and very challenging experience but if thesis supervision is supportive, constructive and productive, many students will enjoy thesis writing and acquire the necessary research skills. Many students also felt that the faculty should adequately prepare them for thesis defence given that many get nervous during defense.

\section{Recommendations}

From the analysis of issues raised by the participants, the following recommendations are made:

- The faculty needs to revamp its research courses to address the knowledge and skills deficit raised by the participants. Perhaps more practice in choosing research topics, identifying and handling related literature and analysing data is needed.

- All M.Ed students should have done a research project in their first degree to provide a basis for the M.Ed thesis.

- Supervisors should render a lot of assistance and support to students during thesis writing and defence . A nurturing attitude and being available most of the time could go a long way in assisting students' thesis writing. 
- Students should be given a lot of thesis-defence practice sessions before they finally defend their theses to the panel of examiners to mitigate the fear and nervousness reported by many in this study.

\section{References}

Brabazon,T. (2010). How not to write a PhD thesis. At the Heart of the Higher Education Debate, 1-6.

Brenman, P. K. (1985). An analysis of relationship among hemispheric and analytical/global cognitive style, method of instruction, gender and Mathematics achievement of tenth grade students. Dissertation Abstracts International, 45, 113271A.

Cohen, L. \& Manion, L. (1997). Research methods in education. London: Groom Helm.

Fishbein, M. (1975). Beliefs, attitudes, intention and behaviour. Philippines. Addison Wesley.

Grant, B. M. (2005). Fighting for space in supervision: Fantasies, fairytales, fictions and fallacies. International Journal of Qualitative Studies in Education, 18(3) 337-354.

Jasonbeck, S. (1984). The effects of right brain Mathematics curriculum on low-achieving fourth grade students. Dissertation Abstracts, $54,2791 \mathrm{~A}$.

Kolb, D. (1987). Using Kolb's learning cycle to improve student learning. Engineering Education, 77, 291-396.

Lee, A. M. (2007). Developing effective supervisors: Concepts of research supervision. South African Journal of Higher Education, 21(4) 680-693.

Mapesela, M. L. E. \& Wilkinson, A. C. (2005). The pains and gains of supervising postgraduate students from a distance: The case of six students from Lesotho. South African Journal of Higher Education, 19,1238-1254.

Moses, I. (1994). Supervision of higher degree students:Problem areas and possible solutions. Higher Educational Research and Development, 3, 153-165.

Okweilagwe, E. A. (2002). Nigerian students' perceptions of academic departments as a teaching and learning environment. Research in Education, 68,1-14.

Pearson, M. \& Kayrooz, C. (2004). Enabling critical reflection on research supervisory practices. International Journal for Academic Performance, 9(1) 099-116.

Rajecki, D. W. (1982). Attitudes: Themes and advances. Massachusetts: Sinaner Associates.

Spear, R. H. (2000). Supervision of Research Students: Responding to Student Expectations. Canberra: Australian National University. Van Dalen, D. B. (1979). Understanding educational research: An introduction. New York: McGraw-Hill. 